\title{
Organizational Climate and Knowledge Sharing towards Employees' Innovative Behavior in Design Industry
}

\author{
Mohamad Hisyam Selamat ${ }^{1} \&$ Yanyu Zhang $^{2}$ \\ ${ }^{1}$ Faculty of Business, Accounting and Management, SEGi University, Malaysia \\ ${ }^{2}$ Faculty of Institute Graduate Studies, SEGi University, Malaysia \\ Correspondence: Yanyu Zhang II, Faculty of Institute Graduate Studies, SEGi University, 47810 Petaling Jaya, \\ Malaysia.E-mail: 603349647@qq.com or zhangyanyu0607@gmail.com
}

Received: June 13, 2019

doi:10.5539/ijbm.v14n9p76
Accepted: July 20, 2019

Online Published: August 5, 2019

URL: https://doi.org/10.5539/ijbm.v14n9p76

\begin{abstract}
This study examined factors affecting innovative behavior amongst employees in Chinese design industry with the mediating effect of knowledge sharing. Its purpose is to motivate employees to work actively and stimulate their desire for innovation. The examined motivational factors were collective effective belief, freedom in decision. Knowledge sharing was included in the framework as the mediating variable. The survey data used in this empirical study were collected from 432 employees engaged in design work (that is, designers working in graphic design company in Shanxi province of China were the main research objects). Multiple regressions were used to analyses the hypotheses. The findings showed that the effect of collective effective belief on employees' innovative behavior was high. Practical enlightenment is to discover the theory, how to stimulate and promote the employees' innovative behavior in the organizational climates, and the organic symbiosis between individuals and collective development in the organizational environment.
\end{abstract}

Keywords: innovative behavior, organizational climate, knowledge sharing

\section{Introduction}

This paper investigates the impact of the organizational climate (collective effective belief, freedom in decision) on employees' innovative behavior, with the mediator variable of knowledge sharing. In the 21 century witnesses the boom of innovative industries, and then Innovation is the driving force of social and economic development. Nowadays, the focus of modern industry competition has from traditional manufacturing industry to knowledge economy, especially in Cultural and Creative Industry, such as publishing, advertising etc. In our country, the development of innovation-driven also becomes the key to the comprehensively deepening reform. In other words, the core competence of graphic designers is innovative talent.

Now has an increasing recognition that innovation capacity in an organization dependent upon the knowledge, skills, and abilities of its employees. Johnson et al. (1996, p.113) stated: "In the service sector, knowledge itself the product and human capital is the dominant form of capital". Garg and Dhar (2017), Garg and Dhar (2014) also argued that employee innovative behavior is a key to the realization of desired organizational goals. On 2018 Boao Forum for Asia, Chinese president Xi made an important speech at the opening ceremony of the annual meeting, he said that: "Be bold in putting things into practice and blazing new trails. Strengthening Top-down, perfect measures to study new situations, solve new problems and make the new breakthrough in an innovative spirit." While, in China, the culture develop depend on the people's innovation, government's support, and national guidance. Among them, knowledge-intensive and value-oriented are important components of cultural and creative industries, as well as the transmission of enterprise staff value chain. However, the research on employees' innovative behavior in the cultural and creative industries in China is limited. Under the innovation is driven by the national environment, how to promote the employees' innovative behavior and how to motivate the employees' innovation passion also the key factors for enterprise long-term development of strong foundation.

From the above discussion it can be seen that to be innovative graphic designers must be highly motivated to collectively and collaboratively identify new design or stylish concept without compromising on product or service quality to the customers. As the purpose of innovation activities is to find a better way to create value, for 
graphic design, human-centered innovative design is its organizational goal, and the work of graphic designers is a process of participation and enjoyment (the sense of contribution, emotional satisfaction, or the complacency). The realization of innovative behavior depends on the cooperation between teams and the promotion of collective consciousness. In this case, the collaboration and communication between graphic designers depend on their free and flexible creative space. This scenario is termed as knowledge sharing (Wang et al., 2014; Drucker, 1999). From this perspective, knowledge sharing is a crucial value in motivating graphic designers to participate in the creative innovation process. In other words, from the perspective of an organization, the integration and sharing of knowledge is a potential incentive and influence to tap individual's innovative consciousness and ability. This study intends to the innovative behavior from the perspective of individuals (innovative behavior of graphic designers). In short, the study aims to examine intrinsic values that foster a sense of knowledge sharing among graphic designers, which in turn motivates them to be more innovative in the workplace.

To achieve the above research aim, a conceptual framework is developed. There into, organizational climate emphasize people's perceptions of groups or job assignments in which they work (Ali \& Patnaik, 2014). It consists of collective effective belief and freedom in decision making (Ali \& Patnaik, 2014). It is argued that this constructs of organizational climate could develop graphic designers' knowledge sharing commitment and in turn innovative behavior. The intrinsic values embedded in the conceptual framework are needed to overcome barriers associated with graphic designers' knowledge sharing awareness and in turn innovative behavior in graphic design companies in Shanxi province of China. Thus it could be said that being equipped with positive collective effective belief, freedom in decision making enables graphic designers to be highly motivated to share knowledge in the workplace and thereafter to be highly equipped with innovative behavior.

\section{Literature Review and Hypotheses}

\subsection{Innovative Behavior}

This research aims to outline specific characteristics of innovation and innovative behavior from the perspective of graphic design industry. In general, the researchers defined innovation as the generation, usage and adoption of new ideas or behaviors (Amabile, 1988; Walker, 2008). Patterson et al. (2017) stated that Innovation must be undertaken in a group and cannot be undertaken independently. That is to say, innovation is considered as a process because the production, development, and implementation of innovation rely on the group or organization. And this process is inferred as the ability to create and develop new and useful ideas which increase the likelihood of innovation.

In the cultural and creative industry, innovation is defined as the process of having ideas that have value, which is influenced by belief, behaviors, professional knowledge and skill and collaborative environment. This is the process of engaging designers' behavior, generating and implementing new ideas, new process, or even new products and services, and eventually new images. Morsy (2015) stated that innovation is a creative step and it is like a cognitive process that includes the thoughts and way of thinking of the designers. Innovative behavior is not only creative expression of ideas but also successful implementation of the involved processes based on the organizational structure. Thus, the creativity is regarded as the creation of ideas while innovative behavior should be a prerequisite for innovation (Morsy, 2015).

From the aforementioned discussion it is clear that Employees' innovative behavior is an expression of the inner creativity of employees (Janssen et al., 2004). It is a method used to develop creative products and a process through which employees generate and implement new ideas to improve the performance or solve work-related problems (Janssen et al., 2004). In today's knowledge-driven economy, maximizing the innovative potential of employees has become a top priority in every organization (Johnston \& Bate, 2013). Implicit in this is the increasing importance of innovative employees to tackle economic downturn and to transform the crisis into an opportunity (Frymire, 2006).

All in all, it could be said that employees' innovative behavior is the basis of innovation in the organization (Amabile et al., 1996; Hunter et al., 2007). This is the process from finding trouble and then fix in a profitable and sustainable manner. Obtaining ideas from the employees is the prerequisite for the success of innovation development in the organization (Tang et al., 2012). Due to the focus of this research is improving graphic designers' innovative behavior the above definition was adopted. It is argued that in current economic environment innovative behavior is the key core of organizational development and competitive ability. Innovative behavior among employees cannot be assessed from the individual perspective but from the whole organizing and directing function of the organization or organizational leadership (Bledow et al., 2009; Parker, 2011; \& Park et al., 2014). In short, as this study focused on graphic designers' innovative behavior, innovation 
was defined as a process that enables successful implementation of creative ideas within the working environment of an organization.

\subsection{Organizational Climate}

As mentioned above the role of organizational climate in influencing knowledge sharing and innovative behavior is significant, which means that employees' perception on the organization, through a combination of internal and external factors, affects their behavior negatively or positively (Sanad, 2016). Sacher (2010) said that "organizational climate illustrates a common dilemma in the effort to understand and describe human behavior in organizations and a cognitive framework consisting of attitudes, values, behavioral norms and expectations shared by organizational members" (p.4). Ali and Patnaik (2014) stated that organizational climates influenced people's perceptions on groups or job assignments in which they work. In other words, organizational climate influences collective consciousness and interpersonal perceptions. As these two values are strongly related to innovation development, this research decided to include organizational climate construct in its conceptual framework. Two intrinsic values were proposed under the organizational climate construct, namely, collective effective belief and freedom in decision making. The definition and description for each value are dealt with in the following two subsections.

\subsubsection{Collective Effective Belief}

The first element of organizational climate construct is collective effective belief. It is collective attitude that put towards the collective action, which indicates the condition within the collective context and interpersonal interactions among the people in the organization. The collective effective belief can be received differently by each organizational member, which is depending on the social environment and interpersonal relationship in the organization. Thus it could be said that collective effective belief can influence graphic designers' intention to share knowledge and to be innovative.

In the organizations, innovative behavior of employees is very complicated because it is conceived and implemented based on a large number of different organizational factors. In the Chinese context, Assouad et al. (2017) found that collective effective belief influenced employees' actions in the workplace whereby it was reflected in what people take for granted. Tzeng (2009) uncovered that collective effective belief was closely related to innovative behavior through the values of faith, trusting intention, motivation and visionary clarity. This result was consistent with AKgün et al. (2016) whereby they found that positive organizational perception (collective effective belief) motivated employees to be more innovative and to be brave in facing challenges in the workplace. Cameron et al. (2003) uncovered significant relationship between positive organizational perception (collective effective belief) and employees' motivation to contribute towards organizational development through the values of transcendence, sense, appreciation and resilience.

Love et al. (2011) found significant role of collective effective belief in influencing knowledge creation and integration, employees' collaboration and ultimately innovation development. In this case, employees' positive subjective experiences and their positive characteristics influenced their participation in organizational activities through the values of gratitude and commitment (Emmons, 2003). Therefore, when studying graphic designers' innovative behavior, collective effective belief should be regarded as a potential antecedent. Nevertheless, the study on the impact of collective effective belief within an organization is still very limited. Besides, the research on collective effective belief, knowledge sharing and innovative behavior has attracted less attention from the empirical researchers. This motivated this research to investigate the relationship between collective effective belief, knowledge sharing and innovative behavior in the practical setting in detail.

From the above discussion it can be seen that there is a potential relationship between collective effective belief, knowledge sharing and innovative behavior among graphic designers in China. This is because, based on the previous empirical findings, collective effective belief can enhance communication among organizational members, increase work efficiency in the workplace and improves interpersonal interaction in the workplace. Therefore, the following hypotheses were suggested:

H1a: There is a significant relationship between collective effective belief and innovative behavior in the graphic design industry in Shanxi province of China.

H1b: There is a significant relationship between collective effective belief and knowledge sharing in the graphic design industry in Shanxi province of China.

\subsubsection{Freedom in Decision Making}

The second element of organizational climate construct is freedom in decision making. The freedom in decision making refers to the members of the organization participate in decision and strategy making as well as share 
resource (Wally \& Baum, 1994). Wally and Baum (1994) found that freedom in decision making influenced knowledge sharing and innovative behavior significantly. Micheli et al. (2012) stated that freedom in decision making is an important aspect to teamwork and innovation development. Additionally, they found positive relationship between freedom in decision making, knowledge sharing and innovative behavior. In this case, freedom in decision making stimulated graphic designers to involve in innovation development actively because they can make decision based on their own wish or creates new things ideas without waiting for a consensus (Micheli et al., 2012). If employees obtain certain power to make decision they will be more committed towards organizational development.

For the innovative task, the employees should be given more freedom to act (Venkatesh et al., 2012). The freedom in decision making increased the outcome of innovative design process. Venkatesh et al. (2012) and Beverland and Farrelly (2011) stated that employees prefer nature, future uncertainty and open thinking during group discussion. Michlewski (2008) uncovered that freedom in decision making encouraged employees to combine new knowledge, classify the information generated through interpersonal activities and in turn improve the ability to share knowledge and engage in innovation work. In short, freedom in decision making makes employees more innovative in the workplace.

Based on the above discussion it could be said that there is a potential relationship between freedom in decision making, knowledge sharing and innovative behavior among employees. This is because freedom in decision making not only represents a completely new working style but also brings new innovative context and improve knowledge sharing. In short it could be said that freedom in decision making has a potential to influence graphic designers' knowledge sharing and in turn innovative behavior in Shanxi province of China. This leads to the following hypotheses:

H2a: There is a significant relationship between freedom in decision making and innovative behavior in the graphic design industry in Shanxi province of China.

$\mathrm{H} 2 \mathrm{~b}$ : There is a significant relationship between freedom in decision making and knowledge sharing in the graphic design industry in Shanxi province of China.

\subsection{Mediating Role of Knowledge Sharing}

As mentioned before, knowledge sharing plays a mediating role in this study. The development and implementation of employees' innovative behavior depend on the dissemination of information and knowledge sharing among employees. In order to gain a competitive advantage, an organization must utilize its organizational knowledge (Muhammad \& Sadia, 2016). That is to say effective knowledge sharing can bring many positive results to an organization. Woodman et al. (1993) said that knowledge is one of the components of individual creativity and social information as the mechanism for sharing the knowledge at an interpersonal level. Thus, in the explicit form (document and database) knowledge is considered as information which can be utilized and exploited to gain competitive advantage in the market (Selamat \& Choudrie, 2007).

Among the process of knowledge management, knowledge sharing has been identified as the most crucial one (Muhammad \& Sadia, 2016), which is defined as the degree to which employees are willing to donate their knowledge and willing to acquire knowledge. Crossan et al. (1999) and Ipe (2003) defined knowledge sharing as the transference of knowledge among individuals, groups, teams, departments, and organizations. Specifically, through the collision of different knowledge among the interpersonal relationship, individuals are more likely to be enlightened and create innovative ideas (Cao, 2015). In short it could be said that knowledge sharing is the degree to which employees are willing to share their tacit and explicit knowledge with others.

During innovation development, good relationship between employees and organization can inculcate sharing behavior among employees. Thus, this research argued that knowledge sharing increases employees' knowledge exchange with each other and in turns their innovative behavior. In this regard, the process of collecting knowledge is referred as "consulting colleagues in order to get them to share their intellectual capital" (Van den Hooff \& de Leeuw Van Weenen, 2004). This process has been considered as a commitment towards organizational innovation and creativity (Cavaliere \& Lombardi, 2015; Lilleoere \& Hansen, 2011). Giustiniano et al. (2016) investigated the way individuals gain knowledge and learn from others and found that knowledge sharing is critical in fostering individual creativity. Thus it could be said that innovation is strongly dependent upon the process by which individuals acquire new knowledge. In turn, knowledge sharing is critical to accomplishing any innovation or in other words knowledge sharing is the foundation of creative thinking, innovation and level of creativity (Marshall \& Rollinson, 2004; Vicari \& Troilo, 2000).

All in all, knowledge sharing, as a potential intellectual capital, has an important impact on the development of 
organizations. This means that the behavior of knowledge sharing is subjective in nature, and in most cases, it needs to be positively influenced and effectively identified in the organization to ensure that the innovation behavior of employees is designed for the enterprise.

To recapitulate this research intended to examine the above concepts of knowledge sharing and innovative behavior in graphic design industry in China. This industry was selected because the success of graphic design companies depends heavily on graphic designers' knowledge sharing commitment and in turn innovative behavior. To develop knowledge sharing and innovative behavior the elements of collective effective belief and freedom in decision making were proposed - antecedents of this research. From this scenario it can be seen that, knowledge sharing represents mediating variable of this research. In short, knowledge sharing has a potential to mediate the relationships between collective effective belief, freedom in decision making and innovative behavior. This argument leads to the following hypotheses:

H3a: The relationship between collective effective belief and innovative behavior is mediated by the knowledge sharing among employees in the graphic design industry in Shanxi province of China.

H3b: The relationship between freedom in decision making and innovative behavior is mediated by the knowledge sharing among employees in the graphic design industry in Shanxi province of China.

\subsection{Relationship between Knowledge Sharing and Innovative behavior}

From the previous research it was found that the innovative behavior of employees largely depends on the interaction between organizations and the encouragement of members to share knowledge with each other (Cao, 2015; Giorgi et al., 2015). In other words, there is a significant influence of knowledge sharing on innovative behavior. Wickramasingle (2015) uncovered that knowledge sharing, and knowledge acquisitions have a positive impact on employees' innovative behavior. Li et al. (2014), through a survey of high-technology enterprises, services industries, and communication industries and other industries, found that knowledge sharing has a very significant positive impact on the employees' innovative behavior. Tu et al. (2015) also found that knowledge sharing has a significantly positive effect on employees' innovative behavior. All these findings lead this research to propose the following final hypothesis:

$\mathrm{H} 4$ : There is a significant relationship between knowledge sharing and innovative behavior among employees in the graphic design industry in Shanxi province of China.

\section{Research Model}

Based on the above, this research conceptual framework was generated which is depicted in Figure 1. The conceptual framework postulates that employees' knowledge sharing within an organization and in turn employees' innovative behavior during the designing task among graphic designers in Shanxi province of China were influenced by organizational climate. The organizational climate consists of the elements of collective effective behavior and freedom in decision making. These independent variables were argued to have positive impact on graphic designers' knowledge sharing (mediating variable) and innovative behavior (dependent variable). In addition, the graphic designers' innovative behavior was considered as the outcome of this research conceptual framework.

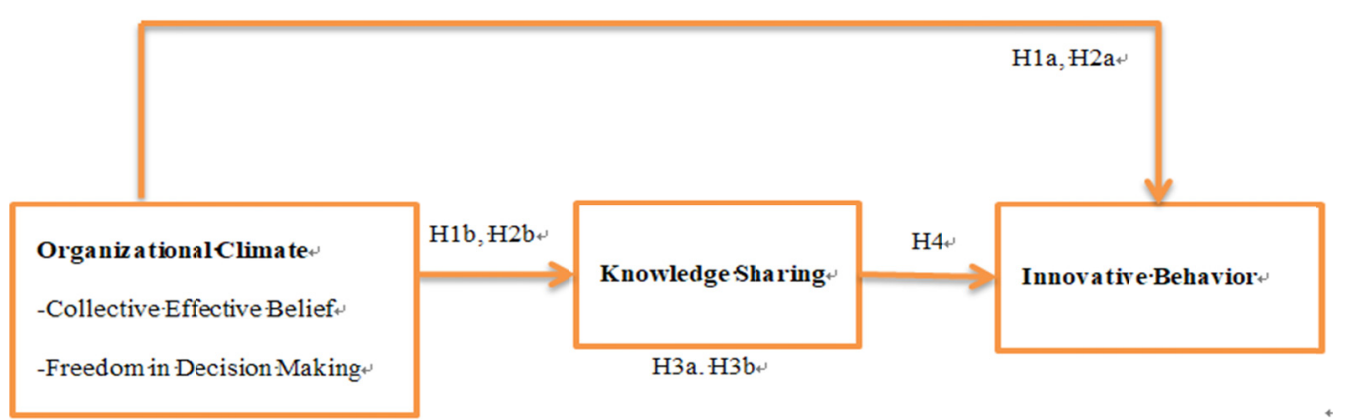

Figure 1. Conceptual framework for promoting innovative behavior among graphic designers in China 


\section{Research Methodology}

\subsection{Sampling and Data Collection}

This research focus on the graphic design industries in Shanxi province of China, thus, the employees of work for the design of private companies of analysis for this study. A cross-sectional survey was adopted during the data collection process. According to the statistical yearbook of Shanxi Province of china, there are 7402 institutions are engaged in the cultural and creative industries and 59,226 employees (Data source statistical yearbook sharing platform: www.yearbookchina.com). This study focused on innovative behavior, only cultural and creative companies were selected and in turn the population of this studies equal to 59,226 employees. Since the analysis units of this research were the graphic designers in the graphic design industry in Shanxi Province, data can be collected from a large number of respondents in a short time by survey approach (Fowler, 2009). In addition, since this study involved hypotheses testing and validation of conceptual framework, survey approach was considered the most suitable one (Dwivedi, 2005). Thus, this research conducted a disproportionate stratified random sampling when distributing the questionnaires. The dataset conjoining measures the impact factors related to employee innovation behavior and knowledge sharing that focuses on the graphic designers' working (outputs) through the activities of work engagement and individuals' technological skill to improve the innovation, with the activities of sharing knowledge (inputs) rather than passive working only, and quantitative data about 28 items concerning innovative behavior, knowledge sharing, collective effective belief, freedom in decision making.

In detail, Gay and Airasian (2000) suggested that the minimum number of subjects in descriptive study samples should be between $10 \%$ and $20 \%$ of the total population, depending on the size of the total population. Hence, according to the calculation of the number of sample size (Nei, 2007), the researcher decided to take a sample size of 533 designers. This is to be more confident in meeting the requirements of statistical technology. Ultimately, out of 533 distributed questionnaires, 432 were returned. This result led to an 81 percent response rate. Sekaran (2003) believed that the response rate of 30\% was sufficient for investigation and research. Based on this recommendation, the response rate of this research $(81 \%)$ was higher than the recommended rate. In turn, the results of the study could be extended to the general public.

\subsection{Research Instrument Reliability}

After reviewing earlier literary theories and works, this study identified and adopted the project of measuring each structure. According to the research proposed in this article, 7 items are adopted to measure innovative behavior (appendix A), adapted from Stephan M (2017). Fourteen items measured organizational climate, i.e., eight items for collective effective belief of the organizational climate constructs (part B of the Appendix), and six items for freedom in decision making of the organizational climate constructs (part $\mathrm{C}$ of the Appendix). All the items were adopted from Sammer and Cario (2015) and adapted to fit the Shanxi province of China. Seven items were used to measure knowledge sharing as a mediating variable (part D of the Appendix). All the items were adopted from Pirkkalainen et al. (2018) and adapted to suit the context of this research. A Likert scale ranging from 1 (strongly disagree) to 7 (strongly agree) was used for these items. In order to improve the quality of the questionnaire, Sekaran (2003) and Straub et al. (2004) suggest that the content validity, pre-test and pilot test were carried out before collecting the original data. Content validity is determined by literature review and expert recommendations (five Ph.D. Management experts). In pre-testing the questionnaire, seven fundamental issues were addressed, namely, the clarity of the statements, the length of the questionnaire, the meaning reflected for each item, the suitability of the scales, the design of the questionnaire, the mistakes in the typing or grammar, and the time needed to complete the questionnaire (Sekaran, 2003). The feedback was used to further improve the questionnaire.

In this research, in order to establish the goodness of measures for testing the research hypotheses, the internal consistency of the factors was examined by conducting reliability analysis. Table 1 exhibits the Cronbach's coefficient alpha of all variables. Nunnaly and Bernstein (1994) suggested that Cronbach's alpha must be greater than 0.6 or $60 \%$ for the instrument to be deemed as acceptable. In overall, the Cronbach's Alpha values for all variables of this study pilot study varied between 0.709 and 0.812 . In other words, none of the variables of this research pilot study demonstrated below the minimum reliability level $(<0.60)$ (Hair et al., 2006). To examine the relationships this study undertook multiple regression whereby. To examine the mediating role of knowledge sharing on the relationships between independent variables and innovative behavior the researchers utilized hierarchical regression. 
Table 1. Research Instrument Reliability

\begin{tabular}{lcccc}
\hline Variable & $\begin{array}{c}\text { N of Original } \\
\text { Item }\end{array}$ & $\begin{array}{c}\text { N of Deleted } \\
\text { Item }\end{array}$ & $\begin{array}{c}\text { N } \\
\text { Items }\end{array}$ & $\begin{array}{c}\text { New } \\
\text { Cronbach } \\
\text { Alpha }\end{array}$ \\
\hline Innovative behaviour & 7 & - & 7 & 0.801 \\
Organizational Climate & & & \\
Collective Effective Belief & 8 & 2 & 6 \\
Freedom in decision making & 6 & - & 6 \\
Knowledge Sharing & 7 & - & 0.709 \\
\hline
\end{tabular}

\section{Data Analysis and Results}

\subsection{Multiple Regression Analyses}

Early in the study, four major hypotheses were proposed. All hypotheses were tested using multiple regressions. Multicollinearity is defined as high correlations amongst two or more independent variables (Hair et al., 2006). Data refinement was performed prior to multiple regression analysis, including data screening and data testing procedures to satisfy the multivariate hypothesis (Hair et al., 2010). Data screening includes missing data, response bias, and outliers identification tests (Hair et al., 2006), while data testing including linearity, normality, homoscedasticity and multicollinearity tests (Hair et al., 2006). This research met the criteria for all these tests.

\subsubsection{Effect of Predictors on Innovative Behavior}

Table 2 illustrates the result of multiple regression analysis to examine the effect of studied predictors on innovative behavior. It is found in the table that the groups of predictors explained 12.3 percent variance in innovative behavior $(\mathrm{R} 2=0.123, \mathrm{~F}=5.991, \mathrm{p}<0.01)$. Eventually, the predictors were collective effective belief $(B=0.123, t=2.287, p<0.05)$ were found to have significant effect on innovative behavior. This result has only supported H1a, whereas, H2a (freedom in decision making) were rejected.

Table 2. Effect of predictors on innovative behaviour

\begin{tabular}{lccc}
\hline & B & t & Sig. \\
\hline Collective Effective Belief & .123 & 2.287 & .023 \\
Freedom in Decision Making & .082 & 1.413 \\
$\mathrm{R}^{2}$ & 0.123 & \\
F & 5.991 & \\
Sig. & 0.000 & \\
\hline
\end{tabular}

\subsubsection{Effect of Predictors on Knowledge Sharing}

Table 3 shows the summary of regression analysis to examine the effect of predictors on knowledge sharing. It is found in Table 3 that all predictors explained 31.3 percent of variance in knowledge sharing $(\mathrm{R} 2=0.313, \mathrm{~F}=$ 19.423, $\mathrm{p}<0.01$ ). Unfortunately, neither predictor had a significant effect on knowledge sharing. In short, H1b (collective effective belief), $\mathrm{H} 2 \mathrm{~b}$ (freedom in decision making) were rejected.

Table 3. Effect of predictors on knowledge sharing

\begin{tabular}{llll}
\hline & B & t & Sig. \\
\hline Collective Effective Belief & .052 & 1.087 & .278 \\
Freedom in Decision Making & -.088 & -1.709 & .088 \\
$\mathrm{R}^{2}$ & 0.313 & & \\
F & 19.423 & & \\
Sig. & 0.000 & & \\
\hline
\end{tabular}

\subsubsection{Effect of Knowledge Sharing on Innovative Behavior}

Result of multiple regression analysis to examine the effect of knowledge sharing on innovative behaviors can be found in Table 4. The result indicated that knowledge sharing explained only 1.6 present of innovative behaviors $(\mathrm{R} 2=0.016, \mathrm{~F}=6.318, \mathrm{p}<0.01)$. Knowledge sharing also acted as the significant predictor to innovative 
behavior $(\mathrm{B}=0.126, \mathrm{t}=2.514, \mathrm{p}<0.05)$. This suggested that $\mathrm{H} 4$ was supported.

Table 4. Effect of knowledge sharing on innovative behavior

\begin{tabular}{llll}
\hline & B & t & Sig. \\
\hline Knowledge Sharing & 0.126 & 2.514 & 0.012 \\
$\mathrm{R}^{2}$ & 0.016 & & \\
$\mathrm{~F}$ & 6.318 & & \\
Sig. & 0.000 & & \\
\hline
\end{tabular}

\subsection{Mediating Effect}

The last hypothesis attempts to examine the mediating effect of knowledge sharing in the relationship between predictors and innovative behavior. In analyzing the mediation effect, hierarchical regression is carried out by Heyes (2013) were adopted to examine the effect of develop employees to share their knowledge as a mediating variable on the relationship between the collective effective beliefs, freedom decision-making and employees' innovative behavior. The first step (equation ' $a$ ') was to examine the relationship between IV to MV. Second steps (equation 'b') was relationship between MV to DV, while third step (equation 'c') between IV to DV). The purpose of Steps 1-3 is to establish that zero-order relationships among the variables exist (Tofighi \& Mackinnon, 2015). The last step (equation c') was the effect of IV on DV with the present of MV. According to the above research, this leads to the following the mediator model as illustrated in Figure2:

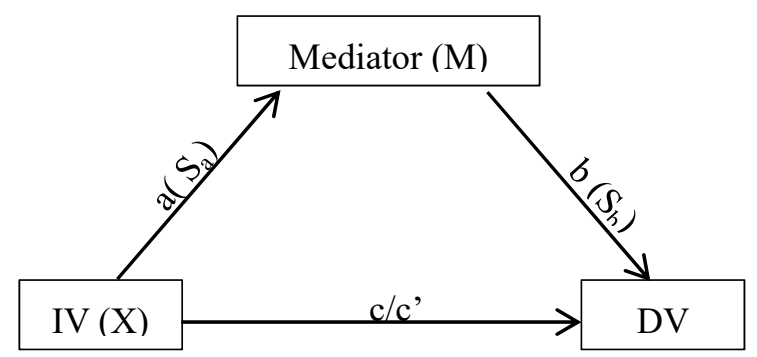

Figure 2. Method used to analyze mediating effect

Result of regression analysis to examine the mediating effect of knowledge sharing commitment is illustrated in Table 5. Out of two dimensions tested, but unfortunately, the valuables of collective effective belief and freedom in decision making failed to fulfill paths. Based on the requirement outlined by Baron and Kenny (1986), knowledge sharing failed to mediate the relationship of variables which were collective effective belief and freedom in decision making with innovative behavior.

Table 5. Mediating effect of knowledge sharing commitment

\begin{tabular}{llll}
\hline & B & t & Sig. \\
\hline Equation a ( IV to MV ) & & & \\
Collective Effective Belief & .052 & 1.087 & .278 \\
Freedom in decision making & -.088 & -1.709 & .088 \\
Equation b (MV to DV) & & & \\
Knowledge Sharing & 0.126 & 2.514 & 0.012 \\
Equation c (IV to DV) & & & \\
Collective Effective Belief & .123 & 2.287 & .023 \\
Freedom in decision making & .082 & 1.413 & .159 \\
Equation c' (X \& M - Y) & & & \\
Collective Effective Belief & .125 & 2.323 & .021 \\
Freedom in decision making & .079 & 1.343 & .180 \\
Knowledge Sharing & -.042 & -.737 & .462 \\
\hline
\end{tabular}




\section{Discussion}

This research from the perspective of the concept of organizational climate, from the organization's common vision, collective effective belief, there into with the free and flexible organizational environment and employees' ability to make decisions freely, this study attempts to explore the knowledge sharing of employees based on the environment of China, and then to enhance the impact of their innovative behavior. Based on the organizational learning theory arguments, a total of 533 questionnaires were distributed in this study, with a recovery rate of $432(81.05 \%)$. The study used data from a survey of 432 designers at graphic design firms in Shanxi Province of China, to answer the research hypothesis.

\subsection{The Effect of Independent Variables on Innovative behavior}

The results show that collective effective belief was positively and significantly influenced innovative behavior of design employees in private graphic design companies in Shanxi province of China. The result of this study was consistent with Kgün et al. (2016), Yuntao et al. (2017) and Thurlings et al. (2015) who found that employees' innovative behaviors were significantly influenced by the organizational atmosphere, in the organizational atmosphere, the collective vision and the common goal of work are related to the organizational members' schematic knowledge and effective belief, as well as the possible behavior of the motivation and intention of the organizational members associated with the collective belief (Roderick, 2010; Weber et al., 2005). On this side, collective effective belief is also regarded as a cognitive construction (Roderick, 2010). This understanding, from the perspective of graphic design companies, creates trust towards other colleagues and employers and ultimately the willingness to invent new innovation collectively.

However, the freedom in decision making was not positively and significantly influenced participation in innovative behavior. The result of this study was not consistent with Kasia et al. (2017), Micheli et al. (2012) and $\mathrm{Li}$ et al. (2008). These studies found that freedom in decision making is one of the critical factors in explaining user behavior and it was mostly reflected in the nature of the process of organizational tasks. The probable explanation could be the organizational culture in the graphic design companies in Shanxi province of China, which stresses on the superiority and seniority during the process of making decision, rational discourse and sharing ideas in the workplace. Thus organizational culture in the graphic design companies in Shanxi province of China need to be changed before freedom in decision making value could give significant impact to innovative behavior among graphic designers.

\subsection{The Effect of Independent Variables on the Knowledge Sharing}

Regrettably, collective effective belief and freedom in decision making were not positively and significantly influenced participation in knowledge sharing. Those finding was not parallel with previous studies such as Wu et al., (2014) Yuntao et al. (2017), Thurlings et al. (2015), Li et al. (2013), Lin (2013), and Yu et al., (2013). These researchers found that collective effective belief has direct significant impact on knowledge sharing, as well as the freedom in decision making is vital for communication within an organization, which improves the sharing and dissemination of knowledge or experience while promoting different ideas. The probable explanation behind the finding of this study could be low trust value among graphic designers in the graphic design companies in Shanxi province of China, and during the working environment and culture in the graphic design companies in Shanxi province of China, which stresses on the superiority and seniority during the process of making decision, rational discourse and sharing ideas in the workplace and high bureaucracy. In turn, the employees feel demotivated to share views because of the concern of being rejected and humiliated by the superior and/or senior members, and then demotivate employees from sharing views and opinions in the organization. Thus working environment and culture in the graphic design companies in Shanxi province of China need to be improved before the collective effective belief and freedom in decision making could give significant impact to knowledge sharing among graphic designers.

\subsection{Mediating Effect of Knowledge Sharing on the Relationship between Independent Variables and Innovative Behavior}

The third research was related to the mediating effect of knowledge sharing on the relationship between independent variables (collective effective belief, freedom in decision making) and the innovative behavior. This study found that hypotheses (collective effective belief, freedom in decision making) were rejected. The probable explanation for all these findings could be the nature of innovative behavior. Thus more attention should be given by the graphic design companies to motivate employees to share knowledge actively in the workplace through employee-friendly working procedure, low bureaucracy and incentives. This could encourage graphic designers to share knowledge actively in the workplace. 


\subsection{The Effect of Knowledge Sharing and Innovative Behavior}

Finally, this research found that knowledge sharing has a positive and significant impact on the participation of innovation behavior. This finding was consistent with previous researchers such as Manteghi (2015), Yuntao et al. (2017) and Tu et al. (2015). Researchers found that knowledge sharing is an effective way to improve the quality of inter-organizational information exchange, solve complex problems and generate innovative behavior through information exchange. Besides, the positive correlation between knowledge sharing and employee innovation behavior has been supported by some experience in various organizations, including research and exploration teams, manufacturing teams and management teams (Gong et al., 2013; Sung \& Choi, 2012). Videlicet, not only does knowledge sharing provide more valuable information for organization members, but the discussion of knowledge sharing can also motivate employees to develop new strategic ways to identify and solve problems.

\section{Conclusions}

\subsection{Managerial and Practical Implications}

In the past, the innovation behavior of employees was mostly extended from the western value system and from the European perspective. This study focuses on the graphic design field of Shanxi Province attempted to develop and present new knowledge concepts from the perspective of China, and focused on the concept of collective and the value of its common vision and belief in the organizational climate. In theoretical aspect, this research has made a positive contribution to academic world as it develops and validates a research instrument for data collection. Another important theoretical contribution of this study is the empirical new motivational factors, namely, collective effective belief, freedom in decision making to the innovative behavior theoretical framework. As discussed in above, these factors have yet to be examined on designers in the graphic design industry in Shanxi province of China. In a word, this is the first research that provides empirical evidence on the importance of these factors in enabling innovative behavior.

In the practical implications, the results of this study have the following important significance for promoting employees' innovative behavior. Firstly, for the strategic development of the company, professionals can make use of the research results of this study to improve the work innovation behavior of employees in the organization team based on the effectiveness of the collective belief in the organization and the knowledge sharing behaviors. Hence, according to the results of this research, based on the one hand, can consider to choose working years longer as organization of the team core personnel, on the other hand, on the working experience can be recognized by other members, in addition, the organization can set out from their actions each other between team lead other members to produce more of the knowledge sharing behavior, and promote the innovative behavior. Secondly, with the augmentation of the region culture influence, the enterprise should be more resources for relationship building, cannot rely on the willingness to unilaterally to enhance its innovation behavior, but should focus on those barriers to restrict its system innovation behavior of (such as the unfair competition environment, the policy protection, or low bureaucracy etc.). Although the results of the survey have not confirmed what the importance of the freedom in decision making in an organization and its potential moderate impact, but we also encourage in the future to better understand the dimensions of Chinese environment, suggested that organization between employees or in the process of various forms of communication with peers to adopt a more open, friendly, caring and interactive way in the aspect of interpersonal relationships by actively help to start the interaction between each other.

\subsection{Limitations and Suggestions for Future Research}

Although this study has certain theoretical and practical implications, it also has some limitations, which can be solved in future studies. The deficiencies of this paper are as follows: First, this study is based on specific context and culture when discussing the factors influencing employees' innovative behavior. According to the interpretation of the study, since the variables in this study were evaluated at the same time, the direction of causality between them could not be determined. For example, employees with innovative behavior more or less affect the sharing and operation of knowledge. In future studies, firstly, longitudinal design can be considered for comparative studies to explore the relationship between them and exclude the order of reverse causality. Then the causal sequence between these structural theoretical frameworks is clarified. And then, longitudinal studies also compare the relationships among different population groups according to different cultural backgrounds. Under the characteristics of China's unique cultural background, considering the dynamic relationship between social status and the different factors of traditional cultural context, a pluralistic comparative analysis of the existing research framework is of great significance to expand the theoretical perspective of innovative behavior theory.

In addition, of this study is based on the knowledge sharing as intermediary variables, but in this study, 
knowledge sharing as an intermediary variable has not been verified. Therefore, through integrated study of debris and the conceptual framework, in the aspect of knowledge sharing should be considered for the handling of all kinds of knowledge, that is to say, in different situations, different motivation provided a more comprehensive explanation. When considering the social network where employees communicate with each other, the knowledge hiding and the traditional Chinese social relations will violate the principle of mutual benefit exchange. Being isolated or lacking in the current needs of the organization will lead to the reduction of knowledge reserve or denial, etc., and they will often provide inappropriate ideas and thus produce a low-quality exchange relationship for the work of employees of the organization. The theoretical reason behind considering the negative effects behind the Chinese traditional environment is the direction of future research. Furthermore, since this research theoretical framework is new, there is a need to further validate it. The theoretical framework of this study can be applied to different industries and organizational departments to conduct textual research from different perspectives and professional aspects.

\section{Acknowledgments}

At the end of this article, I would like to thank Prof. Dr. Hisyam Selamat for his help. His professional help and encouragement helped me to finish this article successfully. Thanks again! And wish you all the best!

\section{References}

Akgün, A. E., Erdil, O., Keskin, H., \& Muceldilli, B. (2016). The relationship among gratitude, hope, connections, and innovativeness. The Service Industries Journal, 36(3-4), 102-123. https://doi.org/10.1080/02642069.2016.1155113

Ali, A., \& Patnaik, B. (2014). Influence of Organizational Climate and Organizational Culture on Managerial Effectiveness: An Inquisitive Study. The Carrington Rand Journal of Social Sciences, 1(2), 1-20. Retrieved from https://s3.amazonaws.com/academia.edu.documents/34555293/DR_AMJAD_ALI.pdf

Amabile, T. M. (1988). A model of creativity and innovation in organizations. Research in Organizational Behavior, (10), 123-167. https://doi.org/10.1515/pcssr-2016-0007

Amabile, T. M., Conti, R., Coon, H., \& Lazenby, J. (1996). Assessing the work environment for creativity. Academy of Management Journal, 39(5), 1154-1184. https://doi.org/10.2307/256995

Assouad, A., \& Parboteeah, P. K. (2017). Religion and innovation. A country institutional approach. Journal of Management, Spirituality \& Religion, 1-18. https://doi.org/10.1080/14766086.2017.1378589

Baron, R. M., \& Kenny, D. A. (1986). The moderator-mediator variable distinction in social psychological research: Conceptual, strategic and statistical considerations. Personality and Social Psychology, 51, 1173-1182. http://dx.doi.org/10.1037/0022-3514.51.6.1173

Beverland, M., \& Farrelly, F. J. (2011). Designers and marketers: Toward a shared understanding. https://doi.org/10.1111/j.1948-7169.2011.00141.x

Bledow, R., Frese, M., Anderson, N., Erez, M., \& Farr, J. (2009). A dialectic perspective on innovation: conflicting demands, multiple pathways, and ambidexterity. Industrial and Organizational Psychology: Perspectives on Science and Practice, 2(3), 305-337. https://doi.org/10.1111/j.1754-9434.2009.01154.x

Cameron, K. S., Dutton, J. E., \& Quinn, R. E. (2003). Foundations of positive organizational scholarship, Positive organizational scholarship, 3-13. San Francisco: Berrett-Koehler.

Cao, K. Y. (2015). The cross level study of the impact of team security on members' innovation behavior: the mediating role of knowledge sharing. Psychological Science, 4, 966-972.

Cavaliere, V., \& Lombardi, S. (2015). Exploring different cultural configurations: how do they affect subsidiaries' knowledge sharing behaviors? Journal of Knowledge Management, 19(2), 141-163. https://doi.org/10.1108/JKM-04-2014-0167

Cavana, R. Y., Delahaye, B. L., \& Sekaran. (2001). Business research: Qualitative and Quantitative Methods. Queensland: John Wiley \& Sons Inc, Milton. https://doi.org/0-471-34126-6

Crossan, M., Lane, H. W., \& White, R. E. (1999). An organizational learning framework: from intuition to institution. Academy of Management Review, 24(3), 522-537. http://www.jstor.org/stable/259140

Drucker, P. F. (1999). Knowledge-worker productivity: The biggest challenge. The Knowledge Management Yearbook 2000-2001, 266-299. https://doi.org/10.2307/41165987

Dwivedi, Y. (2005). Investigating the Research Approaches for Examining. Journal of Research Practice, 1(1), 
D1. http://jrp.icaap.org/index.php/jrp/article/view/4/8

Emmons, R. A. (2003). Positive organizational scholarship: Foundations of a new discipline. In K. S. Cameron, J. E. Dutton, \& R. E. Quinn, Acts of gratitude in organizations (pp. 81-93). San Francisco: Berrett-Koehler.

Fowler, F. J. Jr. (2009). Survey research method. London: Sage Publications.

Frymire, B. (2006, October 7). The search for talent; Business and society. The Economist, 11. https://doi.org/978-1-315-10304-4

Garg, S., \& Dhar, R. (2017). Employee service innovative behavior: the roles of Leader-Member Exchange (LMX), work engagement, and job autonomy. International Journal of Manpower, 38(2). 242-258. https://doi.org/10.1108/IJM-04-2015-0060

Garg, S., \& Dhar, R. L. (2014). Effects of stress, LMX and perceived organizational support on service quality: Mediating effects of organizational commitment. Journal of Hospitality and Tourism Management, 21(C), 64-75. https://doi.org/10.1016/j.jhtm.2014.07.002

Gay, L. R., \& Airasian, P. (2000). Educational research competencies for analysis and application (11th ed.). Upper Saddle River: Prentice-Hall International, Inc.

Giorgi, S., Lockwood, C., \& Glynn, M. A. (2015). The Many Faces of Culture: Making Sense of 30 Years of Research on Culture in Organization Studies. The Academy of Management Annals, 9(1), 1-54. https://dx.doi.org/10.1080/19416520/2015.1007645

Giustiniano, L., Lombardi, S., \& Cavaliere, V. (2016, April). How knowledge collecting fosters organizational creativity. Management Decision, 1464-1496. https://doi.org/10.1108/MD-04-2015-0111

Gong, Y., Kim, T., Lee, D., \& Zhu, J. (2013). A multilevel model of team goal orientation, information change, and creativity. Academy of Management Journal, 56, 827-851. https://doi.org/10.5465/amj.2011.0177

Hair, J. F., Black, W. C., Babin, B. J., Anderson, R. E., \& Tatham, R. L. (2010). Multivariate data analysis. New Jersey: Pierson Hall.

Hunter, S. T., Bedell, K. E., \& Mumford, M. D. (2007). Climate for creativity: a quantitative review. Creativity Research Journal, 19(1), 69-90. https://doi.org/10.1080/10400410709336883

Ipe, M. (2003). Knowledge sharing in organizations: A conceptual framework. Human Resource Development Review, 2, 337-359. https://doi.org/10.1177/1534484303257985

Janssen, O., Van de Vliert, E., \& West, M. (2004). The bright and dark sides of individual and group innovation: a special issue introduction. Organizational Behavior, 25(2), 129-145. https://books.google.com.my/books?isbn=1849505535

Johnson, J., Baldwin, J. R., \& Diverty, B. (1996). The implications of innovation for human resource strategies. Futures, 38(2), 103-119. https://doi.org/10.1016/0016-3287 (95)00083-6

Kasia, T., Gerda, G., Erik, H. J., \& Nachoem, W. M. (2017). Exploration and exploitation activities for design innovation. Journal of Marketing Management, 33(3-4), 203-225. https://doi.org/10.1080/0267257X.2016.1195855

Li, Y., Liu, X., \& Liu, C. (2013). The influence of social interaction motivation on tacit knowledge transfer of knowledge teams. Journal of China Soft Science, 12, 128-137.

Li, Y., Vanhaverbeke, W., \& Schoenmakers, W. (2008). Exploration and exploitation in innovation: Reframing the interpretation. Creativity and Innovation Management, 17(2), 107-126. https://doi.org/10.1111/j.1467-8691.2008.00477.x

Lilleoere, A. M., \& Hansen, H. E. (2011). Knowledge-sharing enablers and barriers in pharmaceutical research and development. Journal of Knowledge Management, 15(1), 53-70. https://doi.org/10.1108/13673271111108693

Lin, H. E., McDonough, E., Lin, S. J., \& Lin, C. (2013). Managing the exploitation/exploration paradox: The role of a learning capability and innovation ambidexterity. Journal of Product Innovation Management, 30(2), 262-278. https://doi.org/10.1111/j.1540-5885.2012.00998.x

Love, J., Roperb, H. S., \& Bryson, J. R. (2011). Openness, knowledge, innovation and growth in UK business services. Research Policy, 40, 1438-1452. https://doi.org/10.1016/j.respol.2011.05.016

Marshall, N., \& Rollinson, J. (2004). Maybe bacon had a point: The politics of interpretation in collective sense 
making. British Journal of Management, $\quad$ 15(S1), https://books.google.com.my/books?isbn=1446246051

Micheli, P., Jaina, J., Goffin, K., Lemke, F., \& Verganti, R. (2012). Perceptions of industrial design: The "Means" and the "Ends". Journal of Product Innovation Management, 29(5), 687-704. https://doi.org/10.1016/j.1540-5885.2012.00937.x

Michlewski, K. (2008). Uncovering design attitude: Inside the culture of designers. Organization Studies, 29(3), 373-392. https://doi.org/ 10.1177/0170840607088019

Muhammad, A. U. H., \& Sadia, A. (2016). A systematic review of knowledge management and knowledge sharing: Trends, issues, and challenges. Cogent Business \& Management, 3(1), 1-17. https://doi.org/10.1080/23311975.2015.1127744

Mustafa Morsy, Y. S. (2015). Innovation, Creativity, and Positive Psychological Capital: Examining the Relationships in Adolescents, Employees and Entrepreneurs. https://d-nb.info/1070214140/34

Nei, T. Z. (2007). Statistical Analysis of SPSS Opinion Survey Using Manual. Taipei: Dingmao Book Publishing Co., Ltd.

Park, S. H., Kim, J. N., \& Krishna, A. (2014). Bottom-up building of an innovative organization: motivating employee intrapreneurship and scouting and their strategic value. Management Communication Quarterly, 28(4), 531-560. https://doi.org/10.1177/089331891451667

Parker, S. C. (2011). Intrapreneurship or entrepreneurship? Journal of Business Venturing, 26(1), 19-34. https://doi.org/10. 1016/j.jbusvent.2009.07.003

Patterson, F., Kerrin, M., \& Gatto-Roissard, G. (2017, January 20). Characteristics\& Behaviors of Innovative People in Organizations. Literature Review prepared for the NESTA Policy \& Research Unit, 1-63. Retrieved from http://www.nesta.org.uk/library

Pirkkalainen, H., Pawlowski, J. M., Bick, M., \& Tannhäuser, A. C. (2018). Engaging in knowledge exchange: The instrumental psychological ownership in open innovation communities. International Journal of Information Management, 38, 277-287. https://doi.org/10.1016/j.ijinfomgt.2017.09.006

Roderick, K. M. (2010). Collective Trust within Organizations: Conceptual Foundations and Empirical Insights. Corporate Reputation Review, 13(2), 82-97. Retrieved from https://books.google.com.my/books?isbn=1118909976

Sacher, A. (2010). Organization climate and managerial effectiveness. Mumbai: Himalaya Publishing House.

Sammer, Y. M., \& Cario, M. M. (2015, March). Innovation, Creativity, and Positive Psychological Capital: Examining the Relationships in Adolescents, Employees and Entrepreneurs. Economics and Management, 263-265. Retrieved from https://d-nb.info/1070214140/34

Sanad, A. A. (2016). Organizational Climate and Its Relationship To Job Satisfaction In Kuwaiti Industrial Companies. Asian Journal of Management Science and Economics, 3(2), 38-47. Retrieved from http://www.multidisciplinaryjournals.com

Sekaran, U. (2003). Research Methods for Business: A Skill-Building Approach (4th ed.). New York: John Wiley \& Sons.

Selamat, M. (2005). Developing individuals for developing learning based systems. School of Information Systems, Computing and Mathematics.

Selamat, M. H., \& Choudrie, J. (2007). Using meta-abilities and tacit knowledge for developing learning based systems: A case study approach. The Learning Organization, 14(4), 321-344. https://doi.org/10.1108/09696470710749263

Straub, D., Boudreau, M. C., \& Gefen, D. (2004). Validation guidelines for IS positivist research. The Communications of the Association for Information Systems, 13(1), 380-427. https://doi.org/10.17705/1CAIS.01324

Sung, S. Y., \& Choi, J. N. (2012). Effects of team knowledge management on the creativity and financial performance of organizational teams. Organizational Behavior and Human Decision Processes, 118, 4-13. https://doi.org/10.1002/job.1897PMID:25598576

Tang, J., Kacmar, K. M., \& Busenitz, L. (2012). Entrepreneurial alertness in the pursuit of new opportunities. Business Venturing, 27(1), 77-94. https://books.google.com.my/books?isbn=1781907870 
Thurlings, M., Evers, A. T., \& Vermeulen, M. (2015). Toward a Model of Explaining Teachers' Innovative Behavior: A Literature Review. https://doi.org/10.3102/0034654314557949

Tofighi, D., \& Mackinnon, D. P. (2015). Monte Carlo Confidence Intervals for Complex Functions of Indirect Effects. Strucatural Equation Modeling: A Muptidisciplinary Journal, 1-12. https://doi.org/10.1080/10705511.2015.1057284

Tu, X., He, X., \& Guo, J. (2015). The influence of critical thinking on employee's innovative behavior: a mediating effect model. Science of Science and Management of S. \& T., 36(10), 169-180.

Tzeng, C. (2009). A Review of Contemporary Innovation Literature: A Schumpeterian Perspective. Innovation, 11(3), 373-394. https://doi.org/10.5172/impp.11.3.373

Van den Hooff, B., \& de Leeuw Van Weenen, F. (2004). Committed to share: commitment and CMC use as antecedents of knowledge sharing. Knowledge and Process Management, 11(1), 13-24. https://doi.org/10.1002/kpm.187

Venkatesh, A., Digerfeldt-Mansson, T., Brunel, F. F., \& Chen, S. (2012). Design orientation: A grounded theory analysis of design thinking and action. Marketing Theory, 12(3), 289-309. https://doi.org/10.1177/1470593112451388

Vicari, S., \& Troilo, G. (2000). Organizational creativity: a new perspective from cognitive systems theory. In G. Krogh, I. Nonaka, \& T. Nishiguchi, Knowledge Creation (pp. 63-89). London: Macmillan.

Walker, R. M. (2008). An empirical evaluation of innovation types and organizational and environmental characteristics: Towards a configuration approach. Research and Theory, 18(4). Retrieved from https://books.google.com.my/books?isbn=1315393360

Wally, S., \& Baum, J. R. (1994). Personal and structural determinants of the pace of strategic decision making. Academy of Management Journal, 37(4), 932-956. https://doi.org/10.2307/256605

Wang, S., Noe, R. A., \& Wang, Z. A. (2014). Motivating knowledge sharing in knowledge management systems: a quasi-field experiment. Management, 40(4), 978-1009. https://doi.org/10.1177/0149206311412192

Weber, J. M., Malhotra, D., \& Murnighan, J. K. (2005). Normal acts of irrational trust: Motivated attributions and the trust development processes. In B. M. Staw and R.M. Kramer (Eds.), Research in Organizational Behavior. Retrieved from https://books.google.com.my/books?isbn=1107023874

Woodman, R. W., Sawyer, J. E., \& Griffin, R. W. (1993). Toward a theory of organizational creativity. Academy of Management Review, 18, 293-321. http://dx.doi.org/10.1108/MRR-01-2013-0025

Wu, C., Parker, S. K., \& de Jong, J. J. (2014). Need for cognition as an antecedent of individual innovation behavior. Journal of Management, 40(3), 1511-1534. https://doi.org/10.1177/0149206311429862

Yu, C., Yu, T. F., \& Yu, C. C. (2013). Knowledge sharing, organizational climate and innovative behavior: A cross-level analysis of effects. Social Behavior and Personality, 41(1), 143-156. https://doi.org/10.2224/sbp.2013.41.1.143

Yuntao, D., Kathryn M, B., Zhi-Xue, Z., \& Chenwei, L. (2017). Enhancing employee creativity via individual skill development and team knowledge sharing: Influences of dual-focused transformational leadership. Journal of Organizational Behavior, 38, 439-458. https://doi.org/10.1002/job.2134 


\section{APPENDIX}

\section{Questionnaire items}

A Items measuring innovative behavior

1. I usually introduce small innovations into my practice.

2. I often succeed in transforming my innovative ideas into practical solutions.

3. I can always able to give a good source of highly creative ideas in my work.

4. I demonstrate originality in my work.

5. I suggest radically new ways of doing things in my work.

6. I am transforming innovative ideas into useful applications.

7. I am introducing innovative ideas into the work environment in a systematic way.

B Items measuring collective effective belief

1. In my department has a strong feeling of "one team".

2. In my department, everyone considers others standpoint.

3. In my department, employees understood and accepted by each other.

4. In my department actively cultivate employees' knowledge diffusion.

5. I am very happy being a member of this organization.

6. This organization has a great deal of personal meaning for me.

7. I have a positive emotional attachment to my organization.

8. Even if I had other better job opportunities, I would want to work with my organization.

C Items measuring freedom in decision making

1. Employees are invited to participate in problem solving and decisions.

2. Supervisor encouraged his subordinates to express their new ideas.

3. Employees have significant autonomy in determining how to do the job.

4. Employees can decide on my own how to go about doing my work.

5. Employees are allowed the flexibility to make direct work-related decisions.

6. Employees are allowed to use their personal initiative and judgment in carrying out their work.

D Items measuring knowledge sharing

1. In my organization, I share and discuss my experiences and special knowledge with others.

2. In my organization, I usually get new knowledge from colleagues.

3. In my organization has expertise in the usage and maintenance of critical information infrastructure, e.g. intranet, groupware (like WeChat, QQ).

4. In my organization, the intranet systems enable the sharing of ideas and critical documents.

5. Knowledge sharing is important for me.

6. I enjoy seeing my colleagues benefit from my knowledge sharing efforts.

7. Sharing knowledge with my colleagues enhances our work relationship.

\section{Copyrights}

Copyright for this article is retained by the author(s), with first publication rights granted to the journal.

This is an open-access article distributed under the terms and conditions of the Creative Commons Attribution license (http://creativecommons.org/licenses/by/4.0/). 